\title{
The Effect of Advance Statistics Learning Integrated Minitab and Excel with Teaching Teams
}

Jackson Pasini Mairing

Mathematics Education Department of Palangka Raya University, Indonesia, jpmairing@math,upr.ac.id

Using statistical software only or Excel only was not effective to increase the learning achievements of undergraduates. The research aimed to describe the effect of using Minitab and Excel with teaching teams toward the undergraduates' achievements of Advanced Statistics course. The research design was an experimental study. The research was conducted in nine stages. The participants were all mathematics education undergraduates from one of the state universities of Palangka Raya in three academic years, i.e. from 2015/2016 to 2017/2018. The instruments were lecture plans, midterm and final tests, and textbook of Advanced Statistics. The conclusion was drawn using covariance analysis and t-test of normalized gain. The research result showed that implementation learning of Advanced Statistics integrated Minitab and Excel with teaching teams increase the undergraduates' achievements in which the normalized gain was more than 0.3 (moderate increasing). In addition, the increase was also indicated by the average differences of the final and the initial scores at the first, the second, and the third years were 7.0, 12.5, and 19.4 respectively. The increase consistently occurred for the three academic years with a confidence level of $95 \%$. The lecture plans could be used as an alternative way to teach Statistics courses.

Keywords: advanced statistics, excel, minitab, teaching teams, undergraduates' achievements

\section{INTRODUCTION}

The era of industrial revolution 4.0 requires undergraduates to have the ability to use ICT (information and communication technology). Lecturers should provide adequate opportunities for undergraduates to acquire the abilities in the classroom (Oldknow, Taylor, \& Tetlow, 2010). The responsibility is not only for lecturers teaching computerrelated courses such as computer programming or mathematics learning integrated with computers. There are big possibilities that undergraduates can also acquire the abilities in other courses such as Basic Statistics or Advanced Statistics.

Citation: Mairing, J. P. (2020). The Effect of Advance Statistics Learning Integrated Minitab and Excel with Teaching Teams. International Journal of Instruction, 13(2), 139-150. https://doi.org/10.29333/iji.2020.13210a 
The Statistics courses contain the procedures of collecting, representing, summarizing, analyzing, and drawing conclusions from the data (Mairing, 2017). The procedures require complex computations using some formulas. The computations are more complex to do by increasing the number of the data, the types of analysis, and the studied variables.

This complexity causes undergraduates finding some difficulties in learning and understanding the courses if such complexity is conventionally studied using pencalculator. For example, undergraduates have to subtract each of the data by its average to determine residuals in the analysis of variance. The results are recorded in a table. Each data is transformed to a standardized normal point $(z)$. All points are recorded in the table. Undergraduates also have to determine the probability between two points of $z$ using the normal distribution table. The probability is re-written into the table in order to examine the normality of the residuals using the Kolmogorov-Smirnov test. If there is an error at a particular step, undergraduates have to repeat the process from the beginning.

Some researchers used statistical software such as Minitab or SPSS to overcome these difficulties (Basturk, 2005; Jatnika, 2015). Using the software had the advantages to help undergraduates understand the characteristics of the data and the results of the data analysis immediately and comprehensively (Mairing, 2013). For example, undergraduates could determine data deviated too far from a mathematical model of regression analysis, and make decision about the data. Was the data discarded, retrieved, or studied separately as an interesting phenomenon? Similarly, undergraduates could also compare two regression equations to determine the best equation represented the diversity of the data. However, the software gave the results of analyzing data immediately without showing their processes. Undergraduates were lack of meaningful understanding of statistical formulas. The condition was one big weakness of using Minitab. Therefore, using the software did not affect their learning achievements (Jatnika, 2015).

The weakness can be overcome by using (Microsoft) Excel. Undergraduates acquire the meaning of statistical procedures by computing some statistics step by step using some formulas in the procedure. The computing is done by translating the formulas to Excel commands. For example, undergraduates determine the statistics of the mean by adding data using Excel command of "sum", then they divide the result by a number of the data using Excel command of " $/$ ". They do not use Excel command of "average" to determine the statistic. Therefore, using Excel does not eliminate the meaning, and still easy for undergraduates to compute statistics using some formulas in the procedure (Chaamwe \& Shumba, 2016).

Using Excel, however, has a weakness that the process can also be time-consuming. The time needed to determine the statistics using Excel is longer than doing the same process using Minitab. In addition, Excel is less flexible in exploring and analyzing data so conclusion drawing takes longer than Minitab does. Thus, the advantage of Minitab can be overcome the weakness and vice versa. 
However, using the software in the classroom has two sides, the first side has a positive impact, while the other side has a negative impact. The software gives a positive impact if its implementation is well-planned. The software should be used to explore and to visualize statistical concepts dynamically, interactively, and attractively. Its use motivates undergraduates in learning, stimulates undergraduates' interest, provides model and image that help undergraduates construct the meaning of concepts or procedures, and increases undergraduates' achievements (Oldknow, Taylor, \& Tetlow, 2010). Conversely, the software gives a negative impact if it is not integrated into learning. Integrating the software in learning is done by having undergraduates learn the statistics using actual research data, making sense of results of analyzing data, and promoting teaching teams to help other undergraduates learn to analyze and to draw conclusions from the data (Pratt, Davies, \& Connor, 2011; Tishkovskaya \& Lancester, 2012).

The success of the learning method integrated with software is influenced and depends on the characteristics of undergraduates (Oldknow, Taylor, \& Tetlow, 2010). Does using software affect the achievements of undergraduates who, most of them, are not used to learn with a computer-based environment? The undergraduates' questionnaire result during three academic years, i.e. from 2015/2016 to 2017/2018, showed that all undergraduates rarely or very rarely learned mathematics integrated with computers when they had studied the subject in the junior and the high schools.

This research implemented Advanced Statistics learning integrated Minitab and Excel with teaching teams to mathematics education undergraduates from one of the state universities in Palangka Raya, Central Kalimantan, Indonesia. The research was carried out during three academic years, i.e. from 2015/2016 to 2017/2018. There were three research questions. Firstly, did the undergraduates' initial abilities affect the final abilities to analyze data? The undergraduates acquired the initial abilities when they learned in Basic Statistics course, whereas the final abilities were in Advanced Statistics course. Basic Statistics is a prerequisite course of Advanced Statistics. Secondly, were the undergraduates' achievements of Advanced Statistics consistent in the three academic years? Thirdly, was there an increase from the initial to the final abilities? The achievements represented the abilities to analyze data. The learning implemented in this research could be used as an alternative method of teaching Statistics courses. The method is expected to increase the undergraduates' achievements and it provides opportunities for them to learn effectively in a computer-based environment.

\section{METHOD}

\section{Research Design}

The research aimed to describe the effect of using Minitab and Excel with teaching teams toward the undergraduates' achievements of Advanced Statistics course. The researcher controlled the independent variable and examined the effect on the dependent variable. The independent variable was learning method using Minitab and Excel with teaching teams that had been applied for the three years, symbolized by $\tau_{I}$, where $i$ was the academic years of $2015 / 2016,2016 / 2017,2017 / 2018$. The dependent variable was 
the achievements of mathematics education undergraduates in Advanced Statistics course from one of state universities at Palangka Raya, Central Kalimantan, Indonesia for the three academic years, symbolized by $y_{i i}$, where $j$ was an index of the undergraduates from 1 to number of undergraduates in each year. Therefore, the research design was experimental study (Lodico, Spaulding, \& Voegtle, 2006).

The conclusions of the research were drawn by covariance analysis and $t$-test of normalized gain. The control variable (covariate) was the undergraduates' initial abilities to analyze data, symbolized by $A_{i j}$. The covariance analysis model was

$$
y_{i j}=\mu+\tau_{i}+\beta A_{i j}+\varepsilon_{i j}
$$

where $\varepsilon_{i j}$ was residuals.

\section{Research Instruments}

The research instruments were lecture plans, midterm and final tests, and textbook of Advanced Statistics course. The plans were integrated Minitab and Excel with teaching teams in the course. Stages of the plans were as follows.

\section{Preparation}

The researcher acted as a lecturer in Advanced Statistics course. The lecturer formed teaching teams. A team consisted of 3-5 undergraduates depending on the number of undergraduates each year.

\section{Before the meeting}

1. The team chose a statistical procedure that they wanted to learn. The choice was based on the procedure used in undergraduates' theses.

2. The team looked for actual research data in accordance with the procedure. The data was typed in Excel, and it shared to the other undergraduates via WhatsApp group.

3. The undergraduates in the team learned to analyze the data using Minitab, Excel, and the textbook by themselves.

4. The undergraduates might find problems in the statistical formulas or the procedures. Therefore, they consulted the lecturer to overcome the problems. They also discussed their comprehension of the results of the analysis. Then, they planned material presented using (Microsoft) PowerPoint by the team.

At the meeting

1. The team presented the actual research data, the research problems, the hypotheses, summary of the research design, and the statistical formulas using PowerPoint.

2. The team demonstrated how to analyze the data using Minitab, and helped the other undergraduates do the same. 
3. The team who had the ability to analyze the data using Excel helped the other undergraduates. One member of the team demonstrated the procedures using Excel commands in front of the class. The other members helped the other undergraduates who had difficulties to operate the commands.

4. After completing the procedures, the undergraduates and the lecturer discussed the meaning of the graphs, the statistics, or the results so the undergraduates acquired a meaningful understanding of the procedure and the results.

5. The undergraduates drew conclusions about the data and the hypotheses.

6. The undergraduates proposed a statistical procedure that they wanted to learn in the next meeting.

The midterm and the final tests were the tasks, actual research data, that the undergraduates were required to analyze using Minitab and Excel for two hours. They should present the data in tables and graphs, summarize it in measures of central tendency and variation, examine assumptions of a statistical test, and make a decision about the hypothesis using the test, and draw conclusions.

\section{Participants}

The participants were all mathematics education undergraduates from one of the state universities in Palangka Raya who took Advanced Statistics course in three academic years, i.e. from $2015 / 2016$ to $2017 / 2018$. The number of undergraduates in each year was 15,18 and 23 respectively.

\section{Procedures}

This research was conducted in nine stages, namely choosing a topic, reviewing the literature, defining research problems, developing research hypotheses, determining participants, developing research instruments, collecting and analyzing the data, making decisions of the hypotheses, and drawing conclusions (Lodico, Spaulding, \& Voegtle, 2006). The conclusions had been drawn by using analysis of covariance and $t$-test of normalized gain.

\section{Data Collection}

There were two data used in this research, namely initial and final abilities to analyze the data. The treatment in this research was the implementation of learning integrated with teaching teams using Minitab and Excel in Advanced Statistics course. The undergraduates began to develop the initial abilities to analyze the data in Basic Statistics which was a prerequisite course of Advanced Statistics. Materials in Basic Statistics were basic knowledge of Statistics, the data presented in tables and diagrams, measures of central tendency and variation, normal and other distributions, statistical hypothesis, the test of normality distribution, the test of variances homogeneity, the inference about two means, and simple linear correlations. The initial abilities were obtained operationally from undergraduates' scores of Basic Statistics, namely the initial scores. 
The final abilities were undergraduates' skills to analyze data after the treatment. The abilities were obtained operationally from undergraduates' scores of Advanced Statistics, namely the final scores. Both of the data were collected during three academic years. Therefore, each undergraduate had two data, namely the initial and the final abilities.

The scoring system of Basic Statistics and Advanced Statistics courses was 20\% of team presentation score, $30 \%$ of mid-test scores, and $50 \%$ of the final-test score. Undergraduates were asked to analyze actual research data using Minitab and Excel in all tests. For example, they were asked to analyze and to draw conclusions from the data using analysis of variance. The analyzing started from presenting and summarizing the data, testing assumptions of the analysis, and drawing conclusions of the hypotheses using Minitab and Excel. They had to solve all stages of analysis in two hours. The scores were based on the number of correct stages from the undergraduates' solutions. The scale of the score was $0-100$. Each score was converted to the quality letter as shown in Table 1.

Table 1

Conversion from Score to Quality Letter

\begin{tabular}{lll}
\hline Interval & Quality letter & Quality score \\
\hline $80 \leq$ score $\leq 100$ & A & 4 \\
$75 \leq$ score $<80$ & B+ & 3,5 \\
$70 \leq$ score $<75$ & B & 3 \\
$65 \leq$ score $<70$ & C+ & 2,5 \\
$55 \leq$ score $<65$ & C & 2 \\
$35 \leq$ score $<55$ & D & 1 \\
$0 \leq$ score $<35$ & E & 0 \\
\hline
\end{tabular}

\section{Data Analysis}

The research used covariance analysis and $t$-test of normalized gain to draw conclusions about hypotheses. The covariance analysis had assumptions which were the covariate independent from the research treatment, normal distribution of the residuals, homogeneity of the variances, and linearity of the model (Rutherford, 2001). The first assumption was fulfilled because the initial abilities of undergraduates (scores of Basic Statistics) were not influenced by the treatment in Advanced Statistics. The second, the third and the fourth assumptions were examined by Kolmogorov-Smirnov test, Levane's test, and lack of fit test respectively. If all assumptions were fulfilled, the researcher examined the first and the second hypothesis using covariance analysis.

The first hypothesis related to the first research question was as follows.

$$
\begin{array}{ll}
H_{10}: \beta=0 & \begin{array}{l}
\text { (There was no linear relationship between the initial and the final } \\
\text { abilities) }
\end{array} \\
H_{11}: \beta \neq 0 & \begin{array}{l}
\text { (There was a linear relationship between the initial and the final } \\
\text { abilities) }
\end{array}
\end{array}
$$


The second hypothesis related to the second question was as follows.

$$
\begin{array}{r}
H_{20}: \tau_{1}=\tau_{2}=\tau_{3}=0 \quad \begin{array}{l}
\text { (The effect of using Minitab and Excel with teaching teams } \\
\text { on the undergraduates' achievements of Advanced Statistics } \\
\text { was the same for all three academic years) }
\end{array} \\
H_{21}: \text { there was at least one } \tau_{i} \neq 0, i=1,2,3 \begin{array}{l}
\text { (There was a different effect on the } \\
\text { achievements of the } \\
\text { undergraduates from at least one of } \\
\text { the academic years) }
\end{array}
\end{array}
$$

Finally, the researcher analyzed the effect of using Minitab and Excel with teaching teams on the abilities of undergraduates to analyze the data based on the normalized gain. The gain was calculated by a certain formula as follows.

$$
G(\text { Normalized Gain })=\frac{\text { the final score- the initial score }}{100-\text { the initial score }}
$$

where the final and the initial scores were obtained from undergraduates' scores of Advanced Statistics and Basic Statistics courses respectively. The third hypothesis related to the third question was:

$$
\begin{aligned}
& H_{30}: G=0.3 \\
& H_{31}: G>0.3
\end{aligned}
$$

where $0.3<G<0.7$ was classified as moderate increase (Mairing, 2017).

The conclusion of the third hypothesis was drawn using the $t$-test. All tests in this research used Minitab 18.

\section{FINDINGS}

\section{Learning Activities}

The researcher acted as a lecturer in the research. At the first meeting, the researcher discussed the course contract including the learning methods and the scoring system. The researcher also informed the reasons for using Minitab integrated with Excel in analyzing data. The researcher briefly introduced Minitab and Excel to the undergraduates. Then, the researcher formed teams of 3-5 undergraduates. This meeting was ended by discussing a statistical procedure that the first team wanted to learn in the next meeting. The researcher asked the team to look for the data from an undergraduate's thesis.

Before the second meeting, the undergraduates in their team learned to analyze the data using Minitab, Excel, and the textbook by themselves. The learning experiences were discussed with the researcher. The undergraduates could ask the researcher about the concepts or formulas in the statistical procedure that had not been understood by them, and the meaning of the results of analyzing data. Finally, the teams and the researcher planned to create a PowerPoint presentation at the second meeting. 
The learning activities at the meetings of 2-7 and 9-15 were accorded with the learning stages. The undergraduates did statistical computations in the learning without using pen, paper, and calculator. All computations were done using Minitab and Excel. At the 8th and 16th meetings, the undergraduates took the midterm and the final tests respectively. The undergraduates solved all the problems on the tests using Minitab and Excel in two hours.

The order of statistical procedures learned by the undergraduates was varied in each year depending on the undergraduates' preferences, and the analysis used in the thesis. In general, the procedures chosen by the undergraduates in the three years of this research were presenting data in tables and graphs, summarizing data, chi-square normality test, Kolmogorov-Smirnov normality test, Pearson correlation, Spearman rank correlation, testing a claim about a mean, inference from two samples, multiple correlation, simple regression, multiple regression, one-way analysis of variance, or Mann-Whitney non-parametric test.

\section{The Analysis of the Initial and the Final Abilities}

The research results showed that the percentage of undergraduates who obtained A, B+ or B from the initial to the final abilities in the first, the second, and the third years were $0 \%, 38.9 \%$, and $43.5 \%$ respectively. Although there was no increase in the first year, there were no undergraduates who obtained $\mathrm{D}$ in the final abilities, whereas there were $6.7 \%$ of the undergraduates in the initial abilities (Table 2). Moreover, the increase from the initial to the final abilities as indicated by the averages of differences in the final and the initial scores in the first, the second, and the third years were 7.0, 12.5, and 19.4 respectively (Graph 1).

Table 2

Percentage of the Undergraduates' Scores in the Three Academic Years

\begin{tabular}{|c|c|c|c|c|c|c|c|c|c|c|c|c|}
\hline \multirow[t]{2}{*}{ Years } & \multicolumn{6}{|c|}{ Initial Abilities } & \multicolumn{6}{|c|}{ Final Abilities } \\
\hline & $\mathrm{A}$ & $\mathrm{B}+$ & $\mathrm{B}$ & $\mathrm{C}+$ & $\mathrm{C}$ & $\mathrm{D}$ & $\mathrm{A}$ & $\mathrm{B}+$ & B & $\mathrm{C}+$ & $\mathrm{C}$ & D \\
\hline $2015 / 2016$ & 46,7 & 26,7 & 20,0 & 0,0 & 0,0 & 6,7 & 66,7 & 13,3 & 13,3 & 0,0 & 6,7 & 0,0 \\
\hline $2016 / 2017$ & 5,6 & 11,1 & 33,3 & 16,7 & 27,8 & 5,6 & 55,6 & 27,8 & 5,6 & 5,6 & 5,6 & 0,0 \\
\hline $2017 / 2018$ & 17,4 & 8,7 & 21,7 & 8,7 & 30,4 & $\begin{array}{l}13, \\
0\end{array}$ & 82,6 & 4,3 & 4,3 & 4,3 & 4,3 & 0,0 \\
\hline All & 21,4 & 14,3 & 25,0 & 8,9 & 21,4 & 8,9 & 69,6 & 14,3 & 7,1 & 3,6 & 5,4 & 0,0 \\
\hline
\end{tabular}

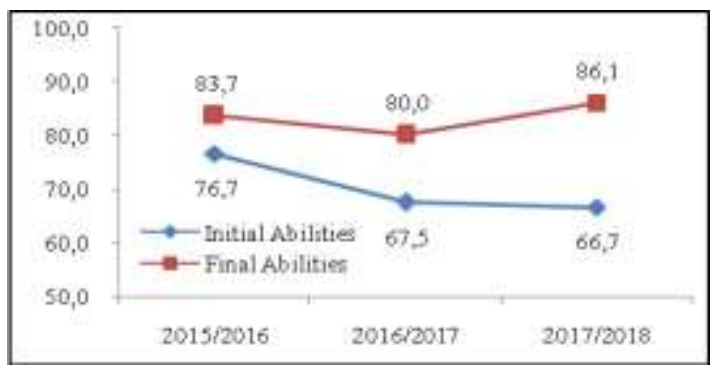

Graph 1

Averages of the Final and the Initial Abilities in the First, the Second, the Third Year 
The first and the second hypothesis were tested using analysis of covariance. Previously, the researcher examined the assumptions. The assumption of normality distribution of residuals was examined by the Kolmogorov-Smirnov test. The result was $p$-value = $0.094 \geq 0.05=\alpha$ meant the residuals had normal distribution with a confidence level of $95 \%$ (Figure 1a). The homogeneity test of the three variances was examined by Levane's test. The result was $p$-value $=0.877 \geq 0.05=\alpha$ meaning that the three variances were homogeneous with a confidence level of $95 \%$ (Figure 1b).

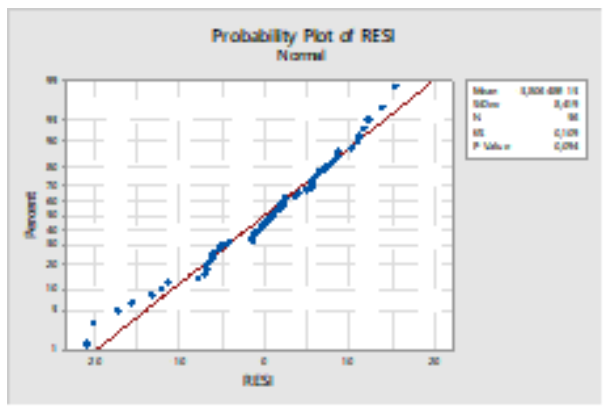

a. Normality test of the residuals

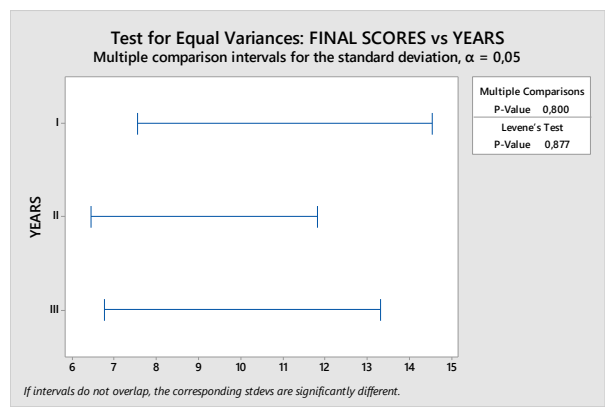

b. Homogeneity test of the three variances

Figure 1

Tests of Assumptions of Covariance Analysis

The lack-of-fit test of the model was obtained $p$-value $=0.5 \geq 0.05=\alpha$ (Table 3) meaning that linearity of the covariance analysis model was fulfilled with a confidence level of $95 \%$. Thus, all assumptions of covariance analysis were fulfilled.

The results of the analysis of covariance were shown in Table 3.

Table 3

Analysis of Covariance

\begin{tabular}{lrrrrr}
\hline Source & DF & Adj SS & Adj MS & F-Value & P-Value \\
\hline Initial abilities & 1 & 298.1 & 298.06 & 3.98 & 0.051 \\
The method in each year & 2 & 425.6 & 212.80 & 2.84 & 0.068 \\
Error & 52 & 3897.9 & 74.96 & & \\
\hline Lack-of-Fit & 46 & 3486.5 & 75.79 & 1.11 & 0.500 \\
Pure Error & 6 & 411.4 & 68.57 & & \\
\hline Total & 55 & 4568.0 & & & \\
\hline
\end{tabular}

The conclusion of the first hypothesis for the covariate (the initial abilities) was obtained $p$-value $=0.051 \geq 0.05=\alpha$ (Table 3$)$ meaning that there was no linear relationship between the initial and the final abilities with a confidence level of $95 \%$. Furthermore, the test of the learning method using Minitab and Excel with teaching teams in each year was obtained $p$-value $=0.068 \geq 0.05=\alpha$ (Table 3 ) meaning that there was no difference in the final abilities of undergraduates in all three years with a confidence level of $95 \%$. 
Table 4

The Result of the Normalized Gain Test

\begin{tabular}{ll}
\hline Null hypothesis & $\mathrm{H}_{0}: \mu=0.3$ \\
\hline Alternative hypothesis & $\mathrm{H}_{1}: \mu>0.3$ \\
T-Value & $p$-Value \\
2.23 & 0.015 \\
\hline
\end{tabular}

The result of the third hypothesis of the normalized gain was shown in Table 4. It showed that $p$-value $=0.015<0.05=\alpha$ meaning that there was an increase in the normalized gain more than 0.3 (moderate increase) with a confidence level of $95 \%$. Therefore, using Minitab and Excel with teaching teams increased the undergraduates' achievements of Advanced Statistics course significantly.

\section{DISCUSSION AND CONCLUSION}

Previous research showed that statistical learning-centered only on the software could improve undergraduates' attitudes towards the application of Statistics, but it could not increase their achievements (Jatnika, 2015). On the other hand, the learning which used Excel was better than statistical software or pen-calculator in terms of the abilities, accessibility, and practicality (Aydin, 2016). This research integrated the use of Minitab and Excel in Advanced Statistics course. The research result showed that using the software affected the undergraduates' abilities to analyze data. The result was in line with the results of previous research stated that ICT-based learning encouraged an active, interesting and effective learning environment for both teachers and undergraduates (Ghavifekr \& Rosdy, 2015). Such an environment could increase undergraduates' achievements (Setambah, Tajudin, Yaakob, \& Saat, 2019).

Using computers in learning needed to be well-planned in order to increase undergraduates' achievements (Gulek \& Demirtas, 2005). The lecturer should plan undergraduates' activities to interact with computers and to involve in lecturer's activities which were guiding undergraduates to understand statistical procedures meaningfully (Chance, Ben-Zvi, Garfield, \& Medina, 2007; Ghavifekr \& Rosdy, 2015). One of the innovative teachings in Statistics learning in the 21 st century was using real data and relevant topics, applying teaching teams, and having undergraduates involved in data collection, and exploring the concepts of Statistics by themselves (Bersales, 2010; Neumann, Hood, \& Neumann, 2013). Such activities were intended to create undergraduates-centered learning (Tishkovskaya \& Lancester, 2012).

The activities were planned by the lecturer in the lecture plans of the research. The undergraduates in teaching teams determined the statistical procedures that they wanted to learn. The determination was based on undergraduates' preferences and the data analysis used in undergraduates' theses. Then, the undergraduates typed and input the data in the thesis using Excel. The teaching teams learned to analyze the data using Minitab and Excel by themselves. The team discussed the results with the lecturer to explore the meaning of the results. The team helped the other undergraduates to learn the statistical procedure using Minitab and Excel, and to understand the results. The lecturer and the undergraduates discussed the processes and the results in order to help 
the undergraduates acquire a meaningful understanding of the statistical procedures and the results.

Finally, the activities had significantly increased the undergraduates' achievements with a normalized gain that was more than 0.3 (moderate increasing). The average of the achievements before using of the two software (the initial abilities) in the first, the second and the third year were 76.7, 67.5, and 66.7 respectively, while after the use (the final abilities) were 83.7, 80, and 86.1 respectively. Therefore, Advanced Statistics learning integrated Minitab and Excel with teaching teams affected the abilities. Furthermore, the effect was not influenced by the initial abilities. It consistently occurred for three academic years. The consistency was shown by there was no difference in the final abilities on all academic years based on the results of covariance analysis.

The lecture plans of the research could be used as an alternative way to teach Statistics courses. The lecturers who wanted to carry out the plans need to pay attention to activities at the first meeting. They should inform clearly the aim of the lecture, the abilities acquired by the undergraduates, the scoring system, and the stages of the lecture plans. In the next meeting, the lecturers should facilitate class discussion so the undergraduates acquired a meaningful understanding of the analysis results.

\section{REFERENCES}

Aydin, S. (2016). Using excel in teacher education for sustainability. Journal of Teacher Education for Sustainability, 18(2), 89-104.

Basturk, R. (2005). The effectiveness of computer-assisted instruction in teaching Introductory Statistics. Educational Technology \& Society, 8(2), 170-178.

Bersales, L. G. (2010). The teaching of statistics in the Philippines: Moving to a brighter future. In C. Reading (Ed.), 8th Internationa Conference on Teaching Statistics ( $\mathrm{p}$. 10A4). Ljubljana, Slovenia: International Statistical Institute.

Chaamwe, N., \& Shumba, L. (2016). ICT integrated learning: Using spreadsheets as tools for e-learning, a case of statistics in microsoft excel. International Journal of Information and Education Technology, 6(6), 435-440.

Chance, B., Ben-Zvi, D., Garfield, J., \& Medina, E. (2007). The role of technology in improving undergraduates learning of statistics. Technology Innovations in Statistics Education, 1(1), 1-26.

Ghavifekr, S., \& Rosdy, W. A. (2015). Teaching and learning with technology: Effectiveness of ICT integration in schools. International Journal of Research in Education and Science, 1(2), 175-192.

Gulek, J. C., \& Demirtas, H. (2005). Learning with technology: The impact of laptop use on undergraduate achievement. The Journal of Technology, Learning, and Assessment, 3(2), 1-35. 
Jatnika, R. (2015). The effect of SPSS course to undergraduates attitudes toward statistics and achievement in statistics. International Journal of Information and Education Technology, 5(11), 818-821.

Lodico, M. G., Spaulding, D. T., \& Voegtle, K. H. (2006). Method in educational research: From theory to practice. San Francisco, CA: John Willey \& Sons, Inc.

Mairing, J. P. (2013). Pembelajaran dengan komputer: dua sisi mata uang [Learning using computer: A two sides]. Seminar Nasional Matematika dan Pendidikan Matematika (pp. 341-349). Yogyakarta, Indonesia: UNY.

Mairing, J. P. (2017). Statistika pendidikan: Konsep dan aplikasinya menggunakan Minitab dan MS Excel [Education Statistics: Concept and its apllication using Minitab and MS Excel]. Yogyakarta, Indonesia: Penerbit Andi.

Neumann, D. L., Hood, M., \& Neumann, M. M. (2013). Using real-life data when teaching statistics; Student perceptions of this strategy in an introductory Statistics course. Statistics Educational Research Journal, 12(2), 59-70.

Oldknow, A., Taylor, R., \& Tetlow, L. (2010). Teaching mathematics using ICT. New York, NY: Continuum International Publishing Group.

Pratt, D., Davies, N., \& Connor, D. (2011). The role technology in teaching and learning statistics. In C. Batanero, G. Burill, \& C. Reading, Teaching statistics in school mathematics-challenges for teaching and teacher education (pp. 97-107). New York, NY: Springer.

Rutherford, A. (2001). Introducing anova and ancova: A GLM approach. London, UK: Sage Publications, Ltd.

Setambah, M. A., Tajudin, N. M., Yaakob, M. F., \& Saat, M. I. (2019). Adventure learning in basic statistics: Impact on undergraduates critical thinking. International Journal of Instruction, 12(3), 151-166.

Tishkovskaya, S., \& Lancester, G. A. (2012). Statistical education in the 21st century: A review of challenges, teaching innovations and strategies for reform. Journal of Statistics Education, 20(2), 1-56. 